\title{
Application of an ionic stabilizer for reinforcing and ensuring frost resistance of clay soils
}

\author{
$V A$ Shorin $^{1, *}$, and $A Y$ Velsovskij $^{1}, T R$ Akhmetov $^{2}$ \\ ${ }^{1}$ Department of Highways, Vologda State University, Lenina ul. 15, 160000, Russia \\ ${ }^{2}$ Kazan State Power Engineering University, str. Krasnoselskaya, 51, 420066, Kazan, Russia
}

\begin{abstract}
This work is devoted to the study of applicability of the Underbold stabilizer for clay soils in the Vologda region, Russia. The influence of the stabilizer on maintaining the ultimate compressive strength of reinforced soils is shown. It depends on the content of clay particles (soil type) and can reach $30 \%$ if the appropriate technology (recommended by the manufacturer) is used. The use of the Underbold stabilizer according to our technology (treatment with a stabilizer - drying - reinforcing with cement) provides an increase in the strength of the reinforced soil after water saturation up to 2 or more times in comparison with samples without a stabilizer. It is shown that when designing a pavement using local clay soils reinforced by the Underbold stabilizer, it is necessary to make a water-insulating layer, and the necessary drainage system to improve the performance of the structural layer. It is noted that this stabilizer does not reduce the phenomenon of frost heaving.
\end{abstract}

\section{Introduction}

Chemical stabilizers have been widely used to reinforce soil in the recent decades. The experience of using this method of reinforcing shows good results [1-7]. Reinforced soils completely exclude the use of crushed stone and gravel during construction of road pavement. As a result, savings on materials, fuel and labor reaches $50 \%$ of the cost of the road as a whole [8,9].

The principle of operation of soil stabilizers consists in an irreversible change of physical and mechanical properties of soil due to the chemical action of the stabilizer solution when it is introduced into the soil $[10,11]$. The impact occurs through ionic replacement of film water on the surface of clay and dusty soil particles by modifier molecules. As a result, clay particles of soil become smaller. The soil after compaction has a higher maximum density than untreated soil, after the same number of roller passes. In addition, the stabilizer molecules that attach to the surface of the clay particle have a water-repellent effect, and the soil particles lose the ability to attract film water to their surface. The soil improved in this way becomes more durable and practically waterproof. It becomes resistant to all climatic conditions and can take an increased payload even in conditions of prolonged and heavy rainfall. The use of the modifier is especially effective for the treatment of plastic and highly plastic heaving clay soils. As a result of soil treatment with a stabilizer, all film water from the surface of clay particles passes into a free state in the soil and is easily removed from it. The degree of heaving and swelling of soils sharply decreases, i.e. the soil is actually transferred to a non-porous state. The
Russian market offers a large variety of foreign and domestic stabilizers. These include LBS soil water repellent (ENVIROSEAL, USA), ANT stabilizer (ANTEngineering LLC, Russia), Consolid (CONSOLID AD, Switzerland), Roadbond EH-1 (USA), Roadbond SPP (joint production of Russia and South Africa), RRP-235 Spesial (Germany), Terrastone (Germany), Dorzin (Ukraine) and others.

The purpose of this work is to study the possibility of using the Underbold stabilizer for clay soils of the Vologda region. This stabilizer was developed in Germany and is successfully used in many countries, where KaHel International is the only licensee to use this harmless, German patented, well-known and fieldproven road construction technology. This product has not yet been tested in Russia, so this study is relevant.

\section{Materials and methods}

We examined 5 types of soils taken from the quarries of the Vologda region. The physical characteristics (moisture at the border of rolling and flow; solid particle density; granulometric composition; maximum density and optimum humidity) of these soils and the degree of heaving were determined in accordance with the Russian State Standarts GOST, Table 1 [12,13]. 
Table 1.

\begin{tabular}{|l|c|c|c|c|c|}
\hline & \multicolumn{5}{|c|}{ No. of soil type } \\
\hline Characteristics & 1 & 2 & 3 & 4 & 5 \\
\hline $\begin{array}{l}\text { Moisture at the border of } \\
\text { rolling, u.f. }\end{array}$ & 0.20 & 0.17 & 0.14 & 0.16 & 0.12 \\
\hline $\begin{array}{l}\text { Moisture at the border of } \\
\text { flow, u.f. }\end{array}$ & 0.39 & 0.28 & 0.26 & 0.23 & 0.17 \\
\hline Index of plasticity Ip, u.f. & 0.19 & 0.11 & 0.12 & 0.07 & 0.05 \\
\hline $\begin{array}{l}\text { Density of soil particles, } \\
\text { g/cm }\end{array}$ & 2.73 & 2.73 & 2.71 & 2.71 & 2.7 \\
\hline Maximum density, g/cm $^{3}$ & 2.2 & 2.03 & 2.01 & 2 & 2 \\
\hline Optimum humidity, u.f. & 0.18 & 0.11 & 0.14 & 0.13 & 0.12 \\
\hline $\begin{array}{l}\text { Relative deformation of } \\
\text { frost heaving, \% }\end{array}$ & 7.9 & - & - & - & - \\
\hline
\end{tabular}

The preparation of the selected soils for testing is performed in the following sequence:

1. The soil is brought to an air-dry state by heating it in a drying cabinet at a temperature of $105^{\circ} \mathrm{C}$. During the drying process, the soil is periodically mixed. The dried soil should have a moisture content not exceeding the values indicated in Table 2 .

Table 2.

\begin{tabular}{|l|c|}
\hline \multicolumn{1}{|c|}{ Soil } & Soil moisture, \% \\
\hline Coarse and medium sized gravelly sand & 4 \\
Fine and silty sand & 6 \\
Sandy loam, light loam & $6-8$ \\
Heavy loam, clay & $10-12$ \\
\hline
\end{tabular}

2. Air-dry soil is ground in a porcelain mortar with a pestle with a rubber tip without pressing on it, in order to separate the individual structural units.

3. The dried and crushed soil is thoroughly mixed to achieve its homogeneity [14].

To reinforce the soil, cement of the grade 500 (the Russian State Standart GOST 10178-85) was used. The technology for preparing soil hardened with an inorganic binder is given in the Russian State Standarts GOST [15].

This technology was changed in accordance with the recommendations on the use of the stabilizer. The technological operations to reinforce the soil with cement using the stabilizer were carried out in the following sequence:

1. Preparation of an aqueous emulsion of the Underbold concentrate (3 parts of concentrate per 100 parts of water).

2. Preparation of a soil sampling with optimal moisture content.

3. Addition of the Underbold emulsion to the prepared soil sampling in a proportion of 501 per $1 \mathrm{~m}^{3}$ of soil and thoroughly mixing.

4. Holding the finished mixture for at least 30 minutes.

5. Addition of a binder to the prepared mixture in the amount of $5 \%$ of the soil volume.

6. Compaction of the ready-made mixture in molds with a standard compaction ratio of 0.98 .

7. Holding the sample for 28 days and testing.
To study the influence of the Underbold stabilizer on water saturation, samples of the reinforced soil were weighed before water saturation (after curing for 28 days) and after water saturation (within 48 hours). Water saturation was determined by the algebraic difference in masses before and after water treatment. The average water saturation was determined as the average for a series of three samples.

To determine the average design resistance, the cross-sectional area of a cube in $\mathrm{cm}^{2}$ and the withstand load in $\mathrm{kN}$ were determined when testing water-saturated samples on a hydraulic press. The average design resistance in $\mathrm{MPa}$ was determined as the average for a series of three samples.

\section{Results and Discussion}

All the obtained experimental results were put in Table 3.

As it can be seen from Table 3, after treatment with a stabilizer the strength increased in almost all samples (an exception is loam with index of plasticity of 7). The greatest difference between the average design resistances of treated and untreated soils was obtained for sandy loam (0.346 MPa) and clay (0.288 MPa). For loams, the difference exists but it is not too large. For loam with index of plasticity 12 , it is $0.063 \mathrm{MPa}$, and for loam with with index of plasticity of 10.5 it is 0.086 $\mathrm{MPa}$.

For clay treated with a stabilizer, water saturation has decreased by a factor of two. Water saturation also decreased in loam with index of plasticity of 7 by $0.15 \%$ and in sandy loam by $0.175 \%$. For loams with plasticity numbers 12 and 11, water saturation increased by 0.03 and $0.092 \%$, respectively.

Fig. 1 shows the experimental results on the influence of different amounts of binder on the strength of the reinforced soil. It is clearly seen that the strength increases with an increase in the percentage of cement in the reinforced soil. So the difference between the average design resistance of soil samples treated with a stabilizer and not treated, is $0.063 \mathrm{MPa}$ for a binder content equal to $5 \%, 0.191 \mathrm{MPa}$ for $7.5 \%$, and 0.492 MPa for a $10 \%$ binder.

Thus, it can be stated with confidence that with an increase in the amount of binder, the soil strength index also increases.

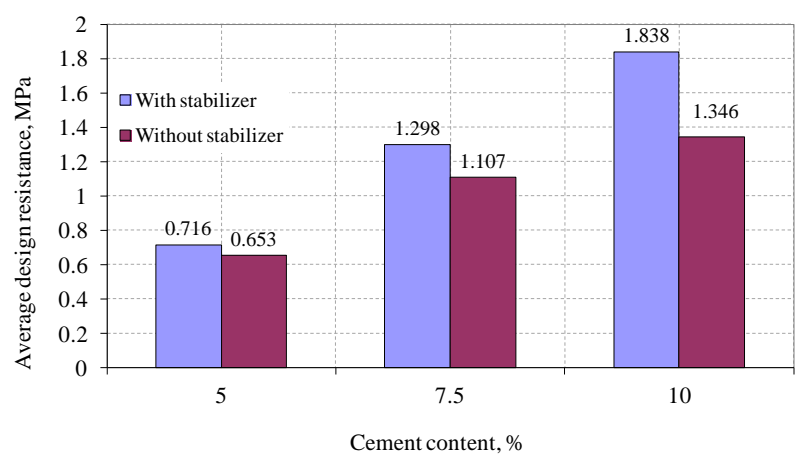

Fig. 1. The influence of different amounts of binder on the strength of the reinforced soil. 
Table 3.

\begin{tabular}{|c|c|c|c|c|c|c|}
\hline \multicolumn{2}{|c|}{ No. } & \multicolumn{3}{|c|}{ Components } & \multirow{2}{*}{$\begin{array}{c}\text { Average } \\
\text { design } \\
\text { resistance, } \\
\mathrm{MPa}\end{array}$} & \multirow{2}{*}{$\begin{array}{c}\text { Average } \\
\text { water } \\
\text { saturation, } \\
\%\end{array}$} \\
\hline $\begin{array}{l}\text { Soil } \\
\text { type }\end{array}$ & Sample & Ip, u.f. & Binder & Stabilizer & & \\
\hline 1 & $1,2,3$ & 0.19 & C $5 \%$ & $2 \%$ & 1.371 & 0.156 \\
\hline 1 & $7,8,9$ & 0.19 & C $5 \%$ & - & 1.083 & 0.354 \\
\hline 3 & $4,5,6$ & 0.12 & C 5\% & $2 \%$ & 0.716 & 0.259 \\
\hline 3 & $10,11,12$ & 0.12 & C 5\% & - & 0.653 & 0.229 \\
\hline 2 & $13,14,15$ & 0.11 & C 5\% & $2 \%$ & 1.002 & 0.586 \\
\hline 2 & $16,17,18$ & 0.11 & C 5\% & - & 0.916 & 0.494 \\
\hline 4 & $19,20,21$ & 0.07 & C 5\% & $2 \%$ & 1.072 & 0.478 \\
\hline 4 & $22,23,24$ & 0.07 & C 5\% & - & 1.677 & 0.628 \\
\hline 5 & $25,26,27$ & 0.05 & C 5\% & - & 1.931 & 0.436 \\
\hline 5 & $28,29,30$ & 0.05 & C 5\% & $2 \%$ & 2.277 & 0.261 \\
\hline 3 & $31,32,33$ & 0.12 & C 7.5\% & - & 1.107 & 0.197 \\
\hline 3 & $34,35,36$ & 0.12 & C $7.5 \%$ & $2 \%$ & 1.298 & 0.261 \\
\hline 3 & $37,38,39$ & 0.12 & C $10 \%$ & - & 1.346 & 0.230 \\
\hline 3 & $40,41,42$ & 0.12 & C $10 \%$ & $2 \%$ & 1.838 & 0.228 \\
\hline 3 & $43,44,45$ & 0.12 & C 5\% & $4 \%$ & 0.605 & 0.365 \\
\hline 3 & $52,53,54$ & 0.12 & C 5\% & $6 \%$ & 0.635 & 0.303 \\
\hline 3 & $55,56,57$ & 0.12 & C $5 \%$ & $2 \%$ & 1.420 & 0.293 \\
\hline
\end{tabular}

The influence of different amounts of Underbold stabilizer on the strength of the reinforced soil is shown in Fig. 2.

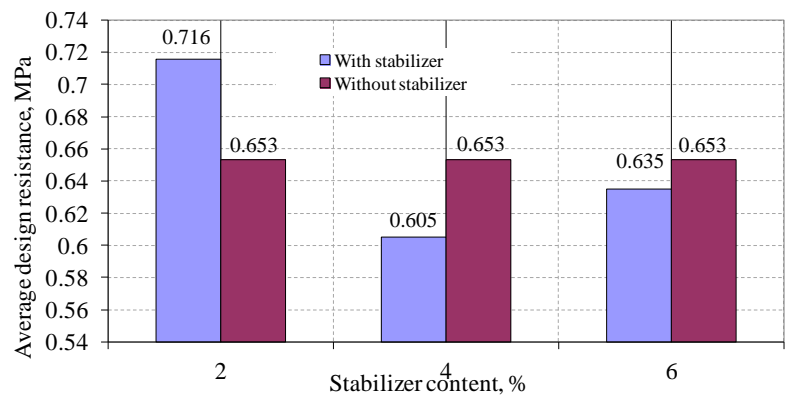

Fig. 2. The influence of the Underbold stabilizer content on the strength of the reinforced soil.

When the amount of stabilizer is increased in two and three times, the average design soil resistance decreases. When the amount of stabilizer is $2 \%$ of the soil mass, the strength increases by $0.063 \mathrm{MPa}$, and at 4 and $6 \%$ it decreases by 0.048 and $0.018 \mathrm{MPa}$, respectively. Therefore, it is necessary to strictly adhere to the recommended technology and to maintain the concentration of the stabilizer indicated by the licensee.

The influence of different amounts of Underbold stabilizer on water saturation of the reinforced soil is analysed in Fig. 3. When the amount of stabilizer is increased in two and three times, the average water saturation increases. When the soil is treated with a stabilizer in the amount of $2 \%$ of the total soil mass, water saturation does not increase significantly by $0.03 \%$. An increase in the amount of stabilizer to $4 \%$ leads to a sharp increase in water saturation by $0.136 \%$. With an increase in the amount of stabilizer to $6 \%$, water saturation increases to $0.74 \%$.

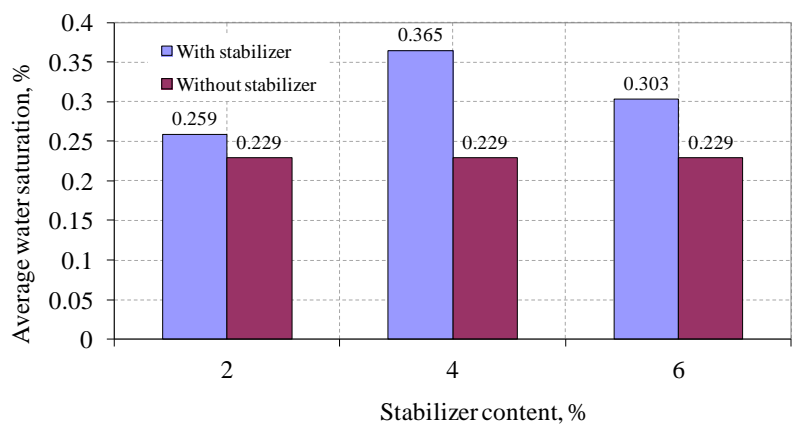

Fig. 3. The influence of Underbold stabilizer content on water saturation of the reinforced soil.

Fig. 4 shows the influence of the technology of clay soil processing with the Underbold stabilizer on the soil strength.

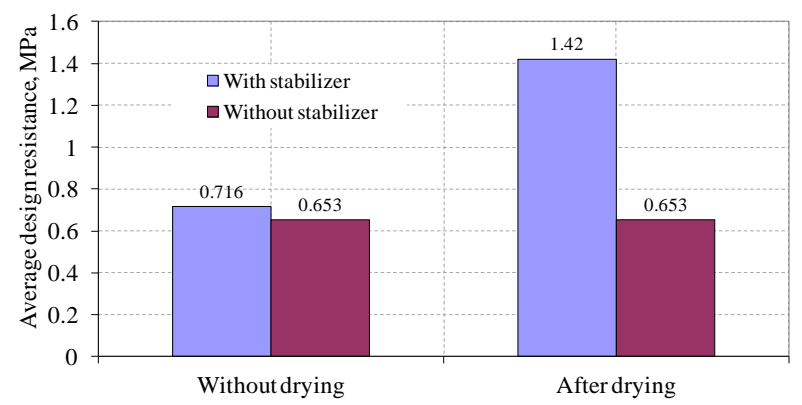

Fig. 4. The influence of the technology of clay soil processing with the Underbold stabilizer on the soil strength.

Six samples were made according to the technology recommended by the stabilizer manufacturer. There exist a difference between the average design resistances, but is not significant. The resistance of samples treated with the stabilizer is $0.063 \mathrm{MPa}$ higher. 
Six samples were produced according to the proposed method (treatment with a $2 \%$ solution of a soil stabilizer brought to optimum moisture content; complete drying of the treated soil; addition a binder (cement) to the optimally moistened soil). The difference between the obtained results is $0.767 \mathrm{MPa}$. This means that when using this technology, the average design resistance of the treated soil increases by 2.5 times compared to that of untreated soil.

The experimentally obtained influence of the technology of clay soil processing with the Underbold stabilizer on the soil strength are shown in Fig. 5.

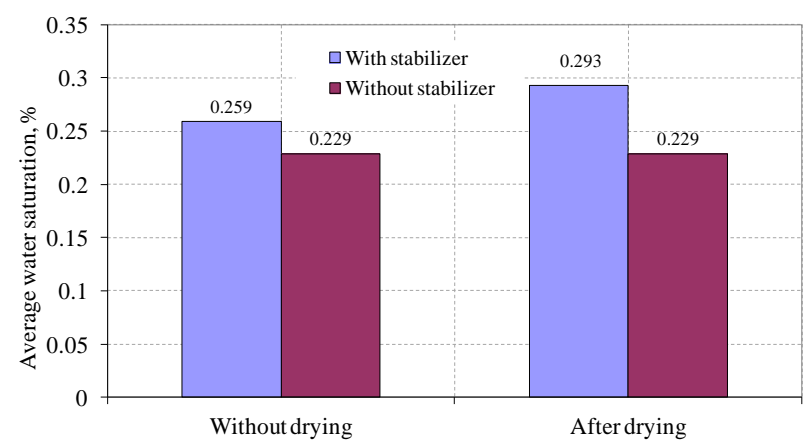

Fig. 5. The influence of the technology of clay soil processing with the Underbold stabilizer on the soil strength.

The results of experimental studies of soil samples before and after stabilization for frost heaving indicators $[16,17]$ are presented in Table 4.

Table 4.

\begin{tabular}{|c|l|c|l|}
\hline No. & \multicolumn{1}{|c|}{ Soil type } & $\begin{array}{c}\text { Relative } \\
\text { deformation of } \\
\text { frost heaving } \\
\varepsilon_{f h}, \%\end{array}$ & \multicolumn{1}{|c|}{$\begin{array}{c}\text { Degree of } \\
\text { frost heaving } \\
\text { of soil }\end{array}$} \\
\hline 1 & $\begin{array}{l}\text { Not treated with } \\
\text { stabilizer }\end{array}$ & 7.9 & $\begin{array}{l}\text { Strongly } \\
\text { swollen }\end{array}$ \\
\hline 2 & $\begin{array}{l}\text { Treated with a } \\
\text { stabilizer according } \\
\text { to Method No. 1 }\end{array}$ & 8.45 & $\begin{array}{l}\text { Strongly } \\
\text { swollen }\end{array}$ \\
\hline 3 & $\begin{array}{l}\text { Treated with a } \\
\text { stabilizer according } \\
\text { to Method No. 2 }\end{array}$ & 4.5 & $\begin{array}{l}\text { Averagely } \\
\text { swollen }\end{array}$ \\
\hline
\end{tabular}

\section{Conclusions}

1. The influence of the Underbold stabilizer on maintaining the compressive strength of reinforced soils depends on the content of clay particles (soil type) and can reach $30 \%$ if the technology recommended by the manufacturer is used.

2. The use of the Underbold stabilizer according to the proposed technology (treatment with a stabilizer drying - reinforcing with cement) provides an increase in the strength of the reinforced soil after water saturation up to 2 or more times compared to samples without a stabilizer.

3. When designing a pavement using local clay soils reinforced with the Underbold stabilizer, it is necessary to make a water-insulating layer.
4. This stabilizer is not a reagent that reduces the phenomenon of frost heaving (a negative result was obtained when tested for frost heaving). To recommend new chemical reagents as anti-icing additives, it is necessary to have the results of experimental determinations of their influence on the heaving properties of soil.

\section{References}

1. S.M. Hejazi, M. Sheikhzadeh, S.M. Abtahi, A. Zadhoush, A simple review of soil reinforcement by using natural and synthetic fibers, Constr. Build. Mater. (2012)

2. J. Li, C. Tang, D. Wang, X. Pei, B. Shi, Effect of discrete fibre reinforcement on soil tensile strength, J. Rock Mech. Geotech. Eng. (2014)

3. N.C. Consoli, M.A. Arcari Bassani, L. Festugato, Effect of fiber-reinforcement on the strength of cemented soils, Geotext. Geomembranes (2010)

4. G.L. Kagan, L.R. Mukhametova, A.Y. Velsovskij, A method for construction of an energy-efficient ice floating pier in the Arctic using hardened ice, E3S Web Conf. 178, 1064 (2020)

5. G.L. Kagan, V.A. Shorin, A.Y. Velsovskij, Effective Design Solutions in the Design of Shallow Foundations, IOP Conf. Ser. Mater. Sci. Eng., 463, 22073 (2018)

6. I. Skrzypczak, W. Radwański, T. Pytlowany, Durability vs technical-the usage properties of road pavements, E3S Web of Conferences (2018)

7. S. Ukolov, S. Shevchenko, D. Simonov, V. Trepalin, L. Yustikova, Joint devices for modular removable road pavement slabs made of polymer materials for agribusiness, E3S Web of Conferences (2020)

8. V.M. Bezruk, I.L. Guryachkov,T.M. Lukanina, Reinforced soils. (Properties and application in road and airfield construction) Moscow Transp. 231 (1982)

9. Anon 2009 Soil strengthening technology "ANT" http://www.ant-rus.com

10. A.A. Firoozi, C. Guney Olgun, A.A. Firoozi, M.S. Baghini, Fundamentals of soil stabilization, Int. J. Geo-Engineering (2017)

11. G.P. Makusa, Soil stabilization methods and materials (2012)

12. V.A. Shorin, G.L. Kagan, Providing frost resistance of road structures (Vologda, 2007)

13. G.L. Kagan, Road permafrost and soil science. Methodical instructions for the implementation of laboratory work on road soil science for students of the specialty (Vologda: VoGTU, 2007)

14. N.S. Biryukov, V.D. Kazarnovsky, Y.L. Motylev, Methodical manual for the determination of physical and mechanical characteristics of soil (Moscow: Nedra, 1975) 
15. Anon 1995 The Russian State Standard GOST 23558-94. Crushed stone-gravel-sand mixtures and soils treated with inorganic binders for road and airfield construction

16. G.L. Kagan, V.A. Shorin, A.Y. Velsovskij, To the question of improvement the normative methodology for calculating the frost resistance of a road structure, E3S Web Conf. 161, 1038 (2020)

17. A. Vel'sovskij, B. Karpov, E. Smirnova, Development of a new method for checking frost heave in roads Proc. Inst. Civ. Eng. - Civ. Eng., 168 49-54 (2015). 